\title{
PARAGANGLIOMA-LIKE DERMAL MELANOCYTIC TUMOR: A RARE SKIN LESION
}

\author{
D.A. Zinovkin ${ }^{*}$, V.S. Aliaksinski², A.K. Hryb ${ }^{2}$, S. Yu. Dedik ${ }^{3}$ \\ ${ }^{1}$ Department of Pathology, Republican Research Center for Radiation Medicine and Human Ecology, \\ Gomel 246040, Belarus \\ ${ }^{2}$ Department of Pathology, Grodno State Medical University, Grodno 230009, Belarus \\ ${ }^{3}$ Department of Pathology, Belarusian State Medical University, Minsk 220116, Belarus
}

Paraganglioma-like dermal melanocytic tumor (PDMT) is a very rare dermal nodule, which resembles clear cell sarcoma and skin melanoma in its morphology. Nowadays about 10 cases of the tumor are described in world literature [1-3].

A 53-year old female patient visited her physician and complained of a dermal nodule on her left thigh. The nodule caused neither discomfort nor pain. Medical history showed that the tumor had existed since her childhood. On physical examination, there was
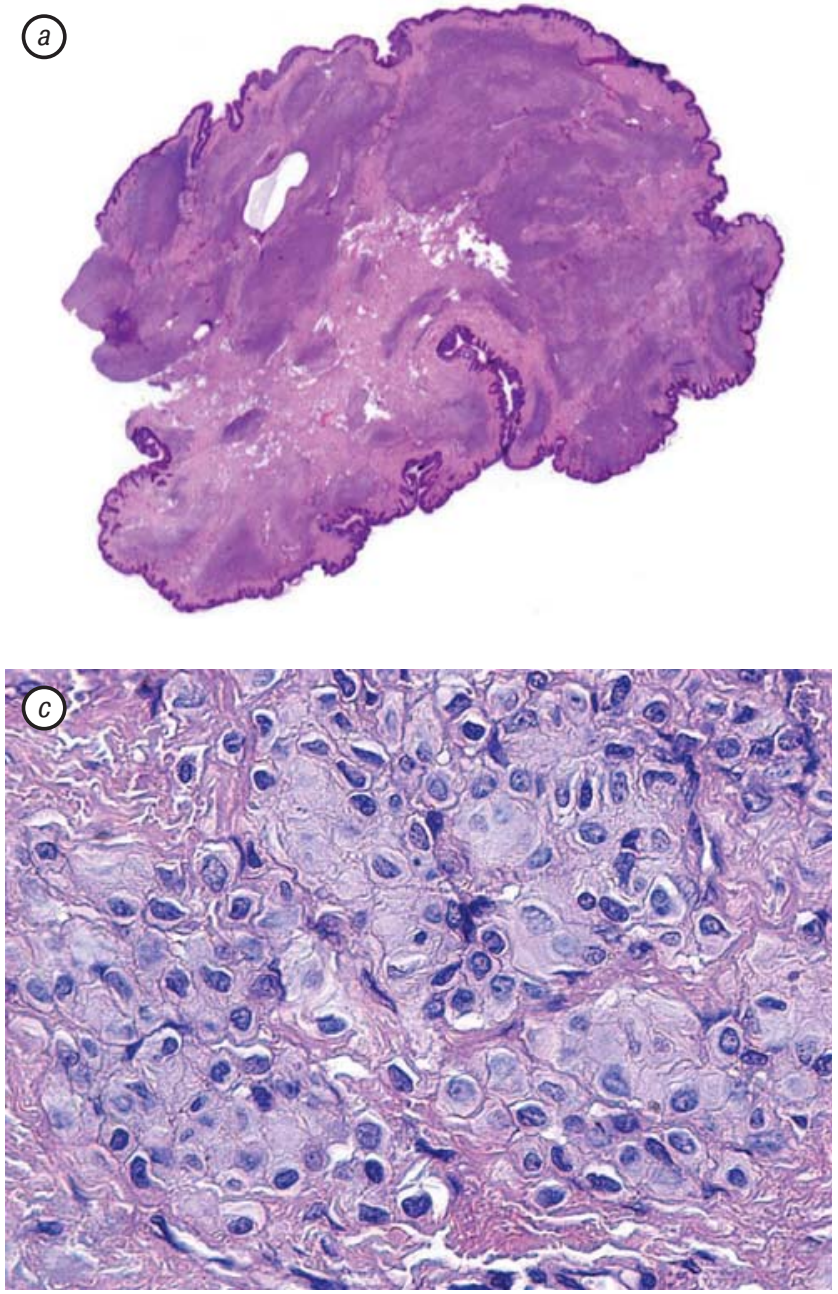

pigmented nodule about $1.2 \mathrm{~cm}$ in diameter, located on a left thigh. The lesion was surgically excised with visually clear margins. Grossly specimen was presented with a pigmented nodule $1.2 \mathrm{~cm}$ in diameter not related to the underlying fascia or ligaments (Fig. 1, a).

Tumor cells did not contain melanin, did not show epidermotropism and were not connected with connective tissue (Fig. 1, b). Microscopically nodule showed nest-like growth pattern (Fig. 1, C), resembling paraganglioma and consisted of clear oval cells slightly
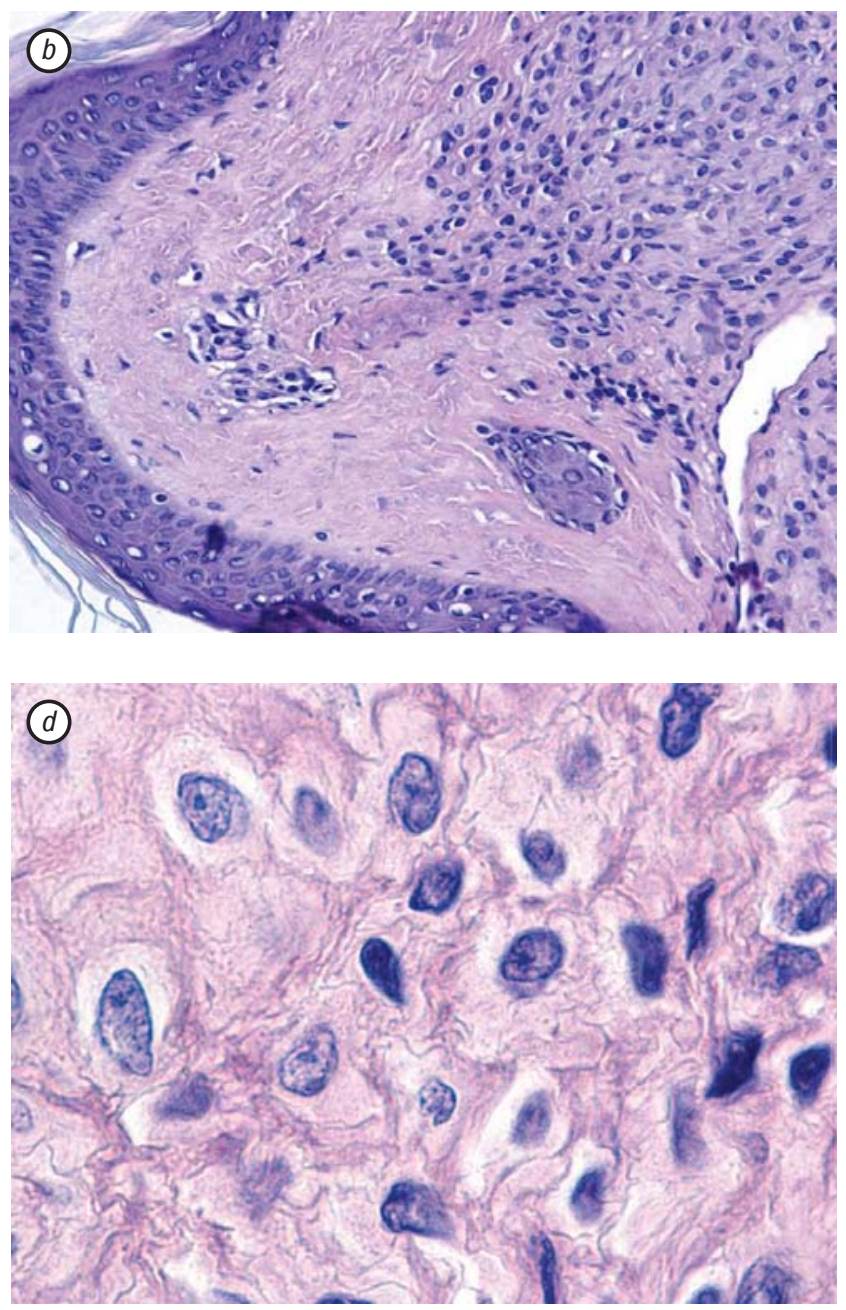

Fig. 1. Microscopic investigation of nodule: $a$ - dermal nodule (haematoxylin and eosin, original magnification $\times 4$ ); $b-$ absence of epidermal junction (haematoxylin and eosin, original magnification $\times 100$ ); $c$ - nest-like growth pattern (haematoxylin and eosin, original magnification $\times 200$ ); $d$ - paraganglioma-like clear oval cells with mild atypia (haematoxylin and eosin, original magnification $\times 1000$, oil immersion)

Submitted: March 16, 2015.

*Correspondence: Tel.: +375291827416

E-mail: zinych007@yandex.ru

Abbreviations used: PDMT - paraganglioma-like dermal melanocytic tumor. 

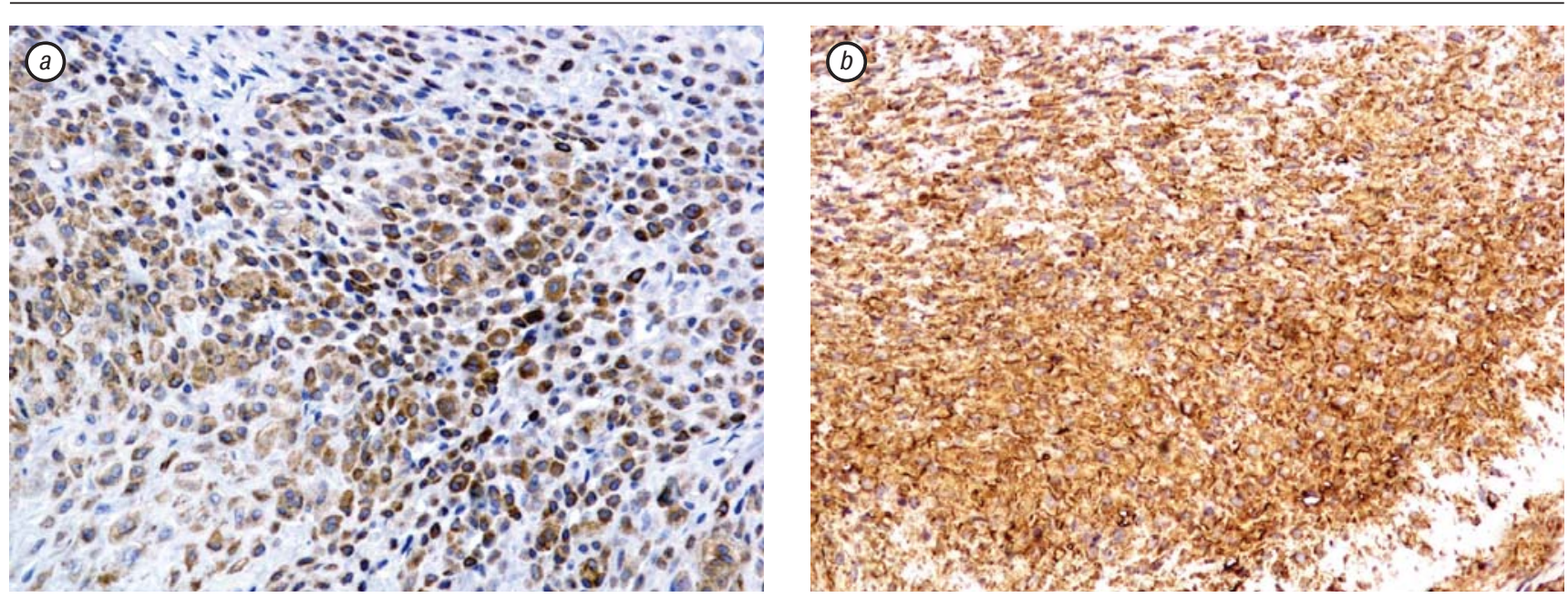

Fig. 2. Immunohistochemical analysis: $a-$ cells are positive for HMB45 (DAB, original magnification $\times 200$ ); $b-$ cells are positive for S100 (DAB, original magnification $\times 200$ )

divided by delicate fibrous strands. Less than 1 mitotic figure was detected at $\times 40$ magnification per 10 fields of vision. For skin contains melanocytes, peripheral nerve fibers, and no ganglions, development of paraganglioma of the skin is unlikely. Mild nuclear atypia (Fig. 1, d) and absence of necroses were observed.

Immunohistochemical staining with HMB45 antibodies showed membranous staining (Fig. 2, a). Melan A staining was negative. Protein $\mathrm{S} 100$ showed strong cytoplasmic in all tumor cells (Fig. 2, b). CD34 was expressed only within vascular endothelium. Expression of SMA and vimentin in tumor stroma and its cells were negative. Concluding all the clinicopathological data we diagnosed the patient with PDMT.

In our opinion, PDMT is a benign dermal tumor. Despite the fact, that American Forces Institute of Pathology considers it as a tumor of uncertain malignant potential the studies show no relapses or metastasizing of the tumor. It is important to note, that PDMT can be mistaken for such malignant tumors as clear cell sarcoma and melanoma [1]. But differential diagnostics of these malignant tumors can be easily performed during the routine hematoxylin and eosin stain. Melanoma is characterized by significant nuclear atypia, high mitotic activity, epidermotropism and absence of nesting pattern, which is inconsistent with PDMT. Clear cell sarcoma is characterized by prominent nucleoli, high mitotic activity, scattered giant tumor cells [2]. We are inclined to think that for more accurate diagnosis of PDMT an immunohistochemical study with Melan A, HMB45, S100, CD34, Desmin, SMA antibodies is necessary. Moreover, PDMT may histopathologically resemble a solid variant of glomus tumor, which sometimes can also be located on lower limbs and have a nesting pattern and mild atypia. Unlike PDMT, glomus tumor has large vessels and positive staining with CD34. Differential diagnostics of this rare benign tumor with melanoma and clear cell sarcoma require increased attention during histopathological study, because mistake can further lead to the wrong highly unnecessary treatment [3].

\section{REFERENCES}

1. Weedon D. Weedon's Skin Pathology. $3^{\text {rd }}$ ed. London: Churchill Livingstone Elsevier, 2010. 1041 p.

2. Deyrup AT, Althof P, Zhou M, et al. Paraganglioma-like dermal melanocytic tumor: a unique entity distinct from cellular blue nevus, clear cell sarcoma, and cutaneous melanoma. Am J Surg Pathol 2004; 28: 1579-86.

3. Cimpean AM, Ceauşu R, Raica M. Paragangliomalike dermal melanocytic tumor: a case report with particular features. Int J Clin Exp Pathol 2010; 3: 222-5. 